\title{
UMA METÁFORA DA CONSCIÊNCIA ${ }^{1}$
}

\section{A METAPHOR OF CONSCIOUSNESS}

\section{UNA METÁFORA DE LA CONCIENCIA}

\section{Edoardo Boncinelli}

O estudo da mente ocupa uma posição muito especial no quadro de nossa tentativa de compreender o mundo. Sobre a mente, e só sobre ela, temos dois tipos diferentes de informações: aquelas que derivam da observação do mundo exterior, a saber, do comportamento dos nossos semelhantes e dos animais, e aquelas que derivam da nossa experiência interior pessoal, isto é, da percepção e, eventualmente, da análise dos nossos pensamentos, sentimentos, motivos e razões. Tendo em conta que temos experiência direta do nosso mundo interior e, dentro de certos limites, da motivação das nossas ações, assumimos que processos análogos aos que observamos em nós mesmos acontecem na cabeça dos nossos semelhantes e, mutatis mutandis, na dos animais com que mais estamos em contato. Assumir isso é fundamental para conduzirmos nossa vida cotidiana, mas, mesmo assim, é algo que assumimos, gerando assim várias dificuldades teóricas, que diferentes pensadores delinearam há tempo, enquanto o nosso tempo as põe impiedosamente em discussão. $\mathrm{E}$ isso a partir do próprio conceito de mente.

\footnotetext{
${ }^{1}$ A tradução para língua portuguesa deste texto original em italiano ( Una metafora della coscienza) é de Selvino José Assmann, doutor em Filosofia pela Pontifícia Università Lateranense, PUL, Itália, professor titular em Filosofia no Departamento de Filosofia (UFSC), professor do Doutorado em Ciências Humanas do Programa de Pós-Graduação Interdisciplinar em Ciências Humanas (UFSC). E-mail: selvinoa@terra.com.br

2 Edoardo Boncinelli (1941-) é docente de Biologia e Genética da Università San Raffaele de Milão (IT), onde também é diretor do Laboratório de Biologia Molecular do Desenvolvimento, tendo sido presidente da Sociedade Internacional de Biofísica e Biologia Molecular, e da Escola Internacional Superior de Estudos Avançados de Trieste (IT). É um importante geneticista, que participa intensamente do debate sobre a relação entre o biológico e o cultural na vida humana. Entre suas obras mais recentes, destacam-se II cervello, la mente e l'anima (Milano, Mondadori, 1999) lo sono tu sei (Milano, Mondadori, 2002), Tempo delle cose, tempo della vita, tempo dell'anima ( Roma, Laterza, 2004), L'anima della tecnica (Milano, Rizzoli, 2006), Il male. Storia naturale e sociale della sofferenza (Milano, Mondadori 2007), L'universo della mente (Roma, Meltemi, 2008), L'etica della vita. Siamo uomini o embrioni (Milano, Rizzoli, 2008), Come nascono le idee (Roma, Laterza, 2008).
} 
Dessa forma, a mente e a psique podem ser estudadas partindo de certo número de pontos de vista diferentes. Pode haver um ponto de vista rigorosamente introspectivo, um especulativo, que combina a observação do comportamento dos outros com a introspecção, e outro mais experimental, que acrescenta à observação e à introspecção o estudo dos êxitos de certo número de experimentos pretendidos. Este é o campo das chamadas ciências cognitivas que recentemente chamaram nossa atenção, revelando-nos uma quantidade de coisas interessantes sobre o cérebro e sobre a mente, e que podemos também definir como o conjunto das atividades cerebrais superiores.

Isso implica que a mente se origina do cérebro, afirmação banal para alguns, mas não para todos. Somos, por isso, levados a perguntar-nos em primeiro lugar o que é o cérebro. Antes de mais nada, o cérebro é um órgão constituído de células, ou - para dizê-lo melhor - de um grande número de células. O córtex cerebral contém, só ele, cem milhões de células nervosas. Em segundo lugar, as células de que é composto o cérebro não são células quaisquer, nem do ponto de vista estrutural, nem do funcional. Trata-se de células feitas para comunicar, que se conectam entre si através de um altíssimo número de contatos, denominados sinapses. Cada neurônio do cérebro contata os outros com uma média de dez mil conexões. Multiplicando o número de neurônios pelo número médio das conexões, chega-se a uma cifra impressionante de um quatrilhão de conexões. Na sua essência mais profunda, o cérebro é, portanto, um elaborador de informações que tem um quatrilhão de conexões.

Quem determina todos esses contatos? Boa parte vem presumivelmente instaurada com base na informação biológica codificada no patrimônio genético do indivíduo, enquanto as conexões restantes devem ser estabelecidas de algum modo com base não genética, como conseqüência direta das várias experiências da nossa vida, incluindo, obviamente, a aprendizagem. É através do estabelecimento e da consolidação desses contatos que aprendemos a falar uma língua particular, italiano, inglês ou russo, aprendemos a saber quem somos, a reconhecer grande número de pessoas e, naturalmente, a apreender um número de noções que nos permitem enfrentar a vida com maior ou menor sucesso.

A impressão que fica a este respeito é que certo número de contatos sinápticos se formam como conseqüência direta das diferentes experiências da nossa vida, enquanto outro número se forma mais ou menos por acaso. Isso deveR. Inter. Interdisc. INTERthesis, Florianópolis, v.6, n.1, p. 1-14, jan./jul. 2009 
se ao fato de que certas conexões são obrigatoriamente formadas dentro de certa idade e, se isso não vier a ocorrer devido à ausência de uma contribuição suficiente de estímulos específicos, formar-se-ão, assim mesmo, de maneira mais ou menos casual. Enorme quantia de contatos sinápticos apresentam-se de fato um pouco diferentes de indivíduo para indivíduo. Por isso, o cérebro de cada um de nós é bastante diferente daquele de qualquer outra pessoa. A combinação de uma diversidade genética, de uma diversidade de experiências de vida e de um não menosprezável componente casual transforma o cérebro de cada um de nós em objeto irrepetível. De toda essa complexidade, da maneira elaborada com que são formadas as diferentes conexões sinápticas, e do seu incrível número, originam-se a nossa autonomia de comportamento e, substancialmente, a nossa liberdade. Sabemos que os organismos inferiores estão vinculados a certas respostas-tipo, mais ou menos estereotipadas e instintivas, enquanto, na proporção em que aumenta a complexidade, diminui drasticamente a importância relativa das respostas instintivas, sempre presentes, em favor de uma série de respostas mais complexas que se apresentam menos predeterminadas, menos abertamente motivadas e mais abstratas. A paleta das respostas comportamentais possíveis acaba enriquecida progressivamente com o aumento da complexidade das espécies, deixando cada vez mais espaço àquilo que costumamos chamar livre arbítrio. A nossa liberdade é, assim, um presente possibilitado pelo nosso patrimônio genético e pelo seu elevadíssimo grau de articulação.

Do ponto de vista científico, só podemos representar o cérebro como um elaborador de informação, uma grandeza física definida operativamente, quantificável e mensurável. Tal afirmação parece óbvia para alguns e insuportável para outros. Para estes, definir dessa maneira o cérebro e mais especificamente a mente parece constituir um crime de "lesa majestade", uma tentativa de banalizar a nossa faculdade mais elevada, e de reduzi-la a uma série de operações típicas de um calculador. O computador recorre à informação derivante de uma determinada quantia de dados na entrada, elaborando-a e utilizando-a com o objetivo de produzir os dados na saída. Tudo o que ocorre entre esses dois eventos pode ser definido como uma elaboração da informação adquirida. Em algumas circunstâncias da vida, nossa mente é realmente usada como instrumento para raciocinar, ou seja, para chegar a conclusões, para resolver problemas e para projetar a execução de tarefas determinadas. Esse aspecto da mente é o mais facilmente analisável sob o ponto R. Inter. Interdisc. INTERthesis, Florianópolis, v.6, n.1, p. 1-14, jan./jul. 2009 
de vista científico e é também o mais fácil de simular com o computador. Podemos chamar de mente computacional o componente das nossas atividades mentais capaz de empenhar-se na realização de tarefas racionais mais ou menos explícitas ou explicitáveis.

Nossa mente é um elaborador de informação que, a fim de alcançar o seu objetivo, precisa de muito mais do que qualquer outro para encontrar um sentido e criar um significado para cada passo desse processo de elaboração. Aparece aqui evidenciada toda a artificiosidade da contraposição entre a concepção da mente como elaboradora de informação e aquela que a considera elaboradora e produtora de significados. Uma coisa não pode existir sem a outra. O computador, pelo contrário, é muito provavelmente um puro e simples elaborador de informação, pois nós o projetamos assim e o vinculamos a este papel. Por outro lado, se é verdade que nossa mente elabora informações e, concomitantemente, produz significados, também é verdade que o conceito de informação está clara e operativamente bem definido, enquanto para o conceito de significado falta, sem dúvida, uma definição clara.

Antes de a transmitir ou elaborar, a informação, da qual se ocupa a nossa mente, deve ser capturada. Isso só poderá acontecer no plano dos sentidos. A informação vem de fora, do mundo exterior. Os nossos sentidos a recebem, e a transportam para o cérebro. Nossos sentidos, porém, não observam o mundo, mas sim o interrogam, buscando respostas precisas a perguntas bem precisas. Nossos sentidos perguntam se tal caixa é amarela ou azul, verde ou vermelha, se aquela linha é vertical, horizontal ou inclinada, se aquele rosto está sorridente ou não. Uma das coisas que foi observada nestes últimos decênios é precisamente a de que nossos sentidos propõem ao mundo circunstante perguntas precisas que devem ser inscritas num esquema bem preciso e codificado. Não são, portanto, apenas os sentidos que são organizados dessa maneira. Também as áreas sensoriais do córtex cerebral e nossos esquemas interpretativos de nível mais elevado são organizados em torno de respostas a perguntas estandardizadas, ditadas pelo nosso patrimônio genético, que é o resultado da nossa evolução biológica. $E$ formulamos naturalmente as perguntas que nos servem, servem para sobrevivermos e para reproduzirmo-nos como um animal com as nossas características. Não colocamos outras perguntas, mesmo que talvez gostássemos de fazê-las, pois a evolução não selecionou aquelas determinadas características biológicas. 
Portanto, nossa mente busca a informação através dos sentidos, mas já traz predefinido o que the interessa e o que não Ihe interessa. Nosso ouvido é sensível às ondas sonoras de certa intensidade e de certa freqüência que chamamos sons. Os morcegos, por sua vez, usam também os ultra-sons, que nós não conseguimos perceber, a fim de localizarem em vôo os obstáculos e as presas potenciais. De maneira semelhante, o nosso olho é sensível às radiações eletromagnéticas de determinado comprimento de ondas, que denominamos luz, enquanto uma abelha também é sensível, por exemplo, aos raios ultravioletas. Por fim, a gama dos odores que conseguimos perceber é ridiculamente limitada com respeito à capacidade de um cão ou de um porco. Na natureza, não existe o odor de frésias, assim como não existem o acorde em Mi ou o amarelo-palha. Cada um deles é um segmento de realidade retalhado por um dos nossos sentidos e elevado por ele ao plano da sensação.

Um feixe de luz branca contém em si potencialmente uma infinidade de raios luminosos de comprimento de onda diversa, mas não contém nem transporta "cores". É nosso olho, ligado ao nosso cérebro, que consegue distinguir as diferentes cores. O mundo por si mesmo não está povoado nem de sensações e nem sequer de estímulos. São os órgãos de sentido das diferentes espécies animais que identificam potenciais estímulos transformando-os em sensações. Conhecemos também casos-limite. Nas rãs, por exemplo, há algumas células nervosas da retina que ficam estimuladas apenas quando o olho vê o movimento veloz de um objeto escuro da dimensão de um inseto contra um fundo relativamente imóvel. Tais neurônios especiais são insensíveis a qualquer outro estímulo semelhante. Para tais células só uma coisa parecida com inseto que voa constitui um estímulo. Todo o restante não o é.

Naturalmente, a informação adquirida através dos sentidos deve ser conservada e oportunamente elaborada. Seria bem interessante delinear também, mesmo que fosse em linhas gerais, o que se aprendeu diretamente sobre esta série de operações, mas não é o lugar para isso. Passemos - isso sim - diretamente a um problema formidável: o da consciência de si ou autoconsciência, o ponto mais elevado e inacessível das nossas atividades cerebrais. Distinguiria pelo menos três 
diferentes significados do termo: a consciência (consapevolezza) ${ }^{3}$, a autoconsciência explicitável compartilhada, e a consciência fenomênica.

Existe sem dúvida uma consciência (consapevolezza) que também pode ser apanágio de muitos animais, mais ou menos conscientes daquilo que estão fazendo ou que estão por fazer. Tal consciência possui muitíssimas gradações e pode ser objeto de observações comportamentais e de outras investigações feitas com as metodologias das neurociências, mas não pode ser objeto de uma conversação (colloquio).

Existe, além disso, uma consciência (coscienza) explicitável, compartilhada pela maioria dos seres humanos adultos. Por termos a capacidade de falar, essa forma de consciência pode ser estudada comportamentalmente, assim como a consciência dos animais e das crianças de menor idade, mas também pode ser objeto de uma conversação. É especialmente mediante a palavra que podemos afirmar termos consciência de ter consciência, ou seja, de termos uma consciência de segundo grau, faculdade que, de modo algum, poderia ser inferida apenas pelo comportamento. É evidente que não pode haver autoconsciência sem consciência, mas obviamente não é verdadeiro o contrário.

Por fim, existe uma consciência fenomênica, privada, intrinsecamente incomunicável, e só acessível pelo interessado direto, ou seja, pelo eu, mediante a introspecção. Observando alguns objetos ou vivendo determinados acontecimentos, posso provar, e realmente provo, sensações muito pessoais muito difíceis de comunicar a outros. Trata-se de uma especial coloração cognitivo-afetiva dos meus estados de consciência, que nos leva a dizer "eu". No momento ainda não está claro se ela é necessária para que nossa mente possa funcionar ou para que qualquer "inteligência" possa funcionar. Os primeiros dois fenômenos - a consciência e a autoconsciência compartilhada - com certeza podem ser estudados cientificamente; não é claro, porém, que isso seja possível no caso da consciência fenomênica.

Há alguns anos propus ${ }^{4}$ o modo como poderíamos pensar o fenômeno da consciência, entendida como autoconsciência compartilhada, o que recentemente retomei e ampliei ${ }^{5}$. Na verdade, não se trata de muito mais do que de uma metáfora,

\footnotetext{
${ }^{3} \mathrm{Na}$ língua italiana existem dois termos para dizer consciência: coscienza e consapevolezza. A primeira é usada quando se prefere falar da realidade moral (coscienza morale), a segunda tem um significado mais geral, psíquico, que é o da consciência de si, daquilo que se faz. [NT]

${ }^{4}$ Cf. BONCINELLI, E. Il cervello, la mente e l'anima. Milano, Mondadori, 1999.

${ }^{5}$ Cf. BONCINELLI, E. lo sono tu sei. Milano, Mondadori, 2002.

R. Inter. Interdisc. INTERthesis, Florianópolis, v.6, n.1, p. 1-14, jan./jul. 2009
} 
mas à falta de algo melhor, até uma metáfora pode ajudar-nos a situar melhor o problema. No mundo dos calculadores, distinguimos um modo de proceder serial de um modo paralelo. O serial, usado por todos os computadores até há pouco tempo atrás, implica a execução de uma série de operações sucessivas: concluído o passo 721, vai-se ao 722 e depois ao 723 , e assim por diante. Por sua vez, o modo paralelo, introduzido mais recentemente no mundo dos calculadores, prevê a execução de diversos programas ao mesmo tempo, que operam paralelamente. $O$ funcionamento paralelo é, obviamente, muito mais rápido, por permitir a execução contemporânea de diferentes operações. O nosso sistema nervoso está organizado desde sempre para que funcione de modo paralelo, permitindo-nos assim que estejamos em contato, em tempo real, com os acontecimentos externos e enfrentemos da melhor maneira possível os fatos da nossa vida.

Chegam ao cérebro, contemporaneamente, muitíssimos sinais provenientes de várias fontes. Há, em primeiro lugar, os sinais que provêm dos sentidos. Mesmo que falemos só de nossa visão, chegam ao mesmo tempo ao córtex cerebral dezenas e dezenas de sinais nervosos diferenciados. Alguns trazem informações sobre o estado de iluminação da cena visível, outros sobre as cores que aí se encontram, outros sobre as formas tridimensionais, outros ainda sobre os detalhes mais ínfimos, e assim por diante. Algo semelhante vale para os outros sentidos e para as sensações e as imagens que foram convocadas naquele exato momento à memória. Qualquer que seja a sua origem, cada sinal apresenta-se como sinal nervoso cuja natureza nos é bastante conhecida e que, pelo menos em linhas gerais, pode ser descrito em cada uma de suas particularidades físico-químicas. A cada um destes sinais dei naquela oportunidade o nome de "neuroestado" ${\text { (neurostato })^{6}}^{6}$

No momento de emergirem à consciência e de virem a ser verbalizados, alguns desses acontecimentos devem, porém, ser alinhados e dispostos em uma seqüência. Sob essa ótica, a consciência corresponde a uma serialização forçada de eventos nervosos e mentais, paralelos por sua natureza. Neste processo, uma coleção mais ou menos extensa de neuroestados transforma-se naquilo que denominei "psicoestados"7 . Pelo jeito, bom tempo passará até que possamos compreender como isso acontece, embora para alguns neurocientistas tais

\footnotetext{
${ }^{6}$ Cf. BONCINELLI, E. Il cervello, la mente e l'anima. Milano, Mondadori, 1999.

${ }^{7}$ Cf. Ibid.

R. Inter. Interdisc. INTERthesis, Florianópolis, v.6, n.1, p. 1-14, jan./jul. 2009
} 
processos pudessem, já hoje, ser compreendidos como resultado de um fenômeno de sincronização da atividade nervosa dos neurônios presentes em certo número de áreas cerebrais diferentes. Segundo essa concepção hipotética, o aparecimento à consciência de uma série de eventos mentais corresponderia à passagem de certo número de grupos de neurônios de um estado de oscilação elétrica desordenado e a-sincrônico para um estado mais ordenado e sincrônico. Quanto mais elevado o número de neurônios sincronizados, tanto mais amplo e profundo seria tal estado de consciência. Sob essa ótica, um psicoestado seria um estado especial de certo grupo de neurônios e dos seus neuroestados momentâneos, e não envolveria nenhum "agente central", nenhum "espectador interior", nenhum "cérebro no cérebro".

Segundo a minha metáfora, a consciência é, portanto, comparável a um "funil" que obriga os processos nervosos paralelos a se alinharem, momentaneamente, em uma seqüência linear, ou seja, serial. Quando penso: "Este é um lápis azul”, uma parte do meu cérebro está ocupado em uma operação serial, a de colocar em fila as cinco palavras em questão. Tal serialização não é nem imediata nem gratuita, mas antes se apresenta como o resultado de uma série de operações. Em condições normais, tudo acontece de maneira muito natural, mas a tarefa apresenta-se muitas vezes mais árdua quando tivermos bebido, quando estivermos sob o efeito de alguns remédios ou então com o passar dos anos. Às vezes, parece que temos muito claro um determinado conceito ou uma determinada imagem, mas não conseguimos logo expressá-los bem, provavelmente porque o referido processo ainda não é completamente serial e implica, por sua vez, um certo grau de paralelismo. A serialização não aparece, portanto, de forma alguma, como automática, e pode exigir algum esforço. Devemos observar, finalmente, que tal serialização forçada de processos paralelos se apresenta como um evento intrinsecamente irreversível. Toda vez que um conjunto de processos paralelos confluir para um estado de consciência não poderá mais ser reconstruído nos seus detalhes. Não se consegue voltar de um psicoestado para os neuroestados que o determinaram. Intimamente conectada com tal processo está, portanto, a sensação interior do tempo que passa, algo que lembra a distensio animi de Santo Agostinho.

A serialização de um grupo de neuroestados é temporária, embora seja legítimo ter como hipótese que o psicoestado que deles derivou possa às vezes deixar alguma marca. À tomada de consciência de um determinado estado de R. Inter. Interdisc. INTERthesis, Florianópolis, v.6, n.1, p. 1-14, jan./jul. 2009 
coisas pode seguir-se uma ação. O cumprimento dela exige a ativação concertada de certo número de músculos, cujo resultado deve, em seguida, ser oportunamente controlado. Por outras palavras, importa que os sentidos, internos e externos, enviem ao córtex as informações necessárias sobre o efetivo andamento da ação. Tem-se, por conseguinte, o desenvolvimento de outro feixe de eventos nervosos paralelos, embora a projeção da ação ainda pertença à consciência e ao momento da serialidade.

Assim, podemos comparar a consciência a uma espécie de "clessidra", e não mais a um funil. Um conjunto de eventos nervosos paralelos é obrigado, por um breve instante, a serializar-se, para dar lugar a uma tomada de consciência e a uma eventual projeção de uma ação; mas, logo depois, tudo retorna ao seu andamento paralelo necessário para o cumprimento da própria ação. O momento da consciência corresponderia, portanto, mais ou menos ao gargalo da clessidra. Antes, tudo é paralelo. Depois, tudo volta a ser paralelo. A contemplação consciente corresponde ao breve momento da serialidade.

Quanto dura este instante? A sua duração fica entre os duzentos e cinquenta milissegundos e uns vinte segundos, mas em geral acontece entre dois e cinco segundos. Um episódio de consciência não pode durar menos de duzentos e cinqüenta milissegundos, por ser este o tempo necessário para que qualquer estímulo, interno ou externo, alcance o córtex cerebral e possa vir a ser "interpretado". Contudo, não pode durar menos de quanto o permita a nossa chamada memória de curto prazo, chamada também memória de trabalho, cuja extensão não supera os vinte segundos. Tal é o lapso de tempo máximo durante o qual podem persistir na nossa mente sensações, pensamentos e recordações que aí tenham aparecido. Transcorrido esse tempo, o episódio de consciência acaba, seguindo-se a ele uma ação, ou sendo o espaço da consciência ocupado por outros conteúdos. De qualquer modo, encerra-se um e abre-se outro. Se pensarmos bem, podemos constatar que boa parte da nossa vida mental é de fato escandida por um ritmo fundamental de três segundos, duração de um verso poético ou de uma frase musical ${ }^{8}$.

Com o objetivo de designar esse estado de coisas, introduziu-se recentemente o conceito de "presente dinâmico", presente entendido como coleção

\footnotetext{
${ }^{8}$ Cf. BONCINELLI, E. Tempo delle cose, tempo della vita, tempo dell'anima. Roma, Laterza, 2003.

R. Inter. Interdisc. INTERthesis, Florianópolis, v.6, n.1, p. 1-14, jan./jul. 2009
} 
de episódios de consciência, representando, cada um deles, um átomo de tempo interior, uma breve janela temporal de contornos quase imperceptíveis. Os eventos neste caso materializam-se por algum instante e depois refugiam-se no passado. Em cada átomo de presente, percebemos um fragmento de realidade que é o resultado da integração dos nossos processos de elaboração da informação, frequentemente fragmentários e incoerentes, como percepções, recordações, expectativas e esquemas interpretativos. A memorização das lembranças e a eventual reevocação, sucessiva às mesmas, dependem intimamente desse processo de identificação de um estado de consciência, mesmo que seja momentâneo. O que não conseguiu emergir claramente em pelo menos um estado de consciência, nunca será memorizado de modo explicitável. De toda forma, é como se nunca tivesse existido. A serialização forçada de eventos neuronais paralelos é, de fato, um processo dinâmico que forja sintática e semanticamente nossa percepção do mundo circunstante e das nossas ações, além da sua memorização. Interessa observar que talvez sejam estas operações aquelas que instituem o passado, na sua qualidade de coleção dos eventos que, pelo menos uma vez, estiveram presentes à consciência, começando por aquelas de arquivamento mais imediato, e que representam o biombo móvel entre futuro e passado, ou seja, o agora.

Um específico ato de consciência pode surgir porque somos atingidos por um evento específico, por exemplo, um som improviso ou uma lâmpada que se acende. A partir desse momento, o episódio começa a desenrolar-se. Trata-se essencialmente de um jogo de confirmações ou desconfirmações das expectativas do que está por acontecer com base no que sabemos e nas nossas experiências pessoais. Enquanto os estímulos provenientes de fora se conformam, com maior ou menor aceitação segundo nossas expectativas e segundo nossa capacidade de os interpretar, a bolha de presente mantém-se intacta. Contudo, basta que se registre uma séria discrepância entre os resultados e as expectativas, a bolha explode e o episódio termina. Os seus conteúdos acabam sendo transferidos, com maior ou menor eficiência, para a memória sob forma de frase, de imagem ou de instantânea da nossa vida, e inicia novo episódio do presente dinâmico e outra aventura interpretativa. $O$ que se mostrou especialmente adequado para analisar tais fenômenos foi o estudo da linguagem, mas não se trata aqui de entrar em pormenores a respeito. 
O que denominamos consciência ou vida interior é, por conseguinte, uma coleção de átomos de presente. Cada átomo de presente inicia, mantendo-se por algum instante e decai, concedendo espaço mental para outro átomo de presente. Não temos consciência alguma dessa fragmentação da nossa consciência. Ela aparece-nos como um continuum, e até mesmo como um continuum presente. Isso deve-se ao fato de que uma das funções principais do nosso córtex cerebral consiste em nos fornecer uma visão mais "razoável", unitária e contínua dos conteúdos da nossa vida mental interior. É possível que também devamos a essa função a existência dos estados parciais de consciência, que denominamos sonhos. Eles poderiam não ser mais do que feixes de neuroestados ativos durante algumas fases do sono que se aproximam da consciência e são por ela parcialmente serializados, e por isso quase forçadamente "racionalizados" e interpretados. É interessante salientar, a esse propósito, que todo episódio de consciência vive normalmente de três elementos: uma fonte - externa ou interna -, uma elaboração, e uma interpretação. No sonho, verifica-se prevalecentemente este último elemento, enquanto o primeiro pode estar totalmente ausente. Se isso for verdade, a análise dos sonhos nos trará mais luz sobre o estado de consciência do momento do indicador, do que sobre o seu inconsciente.

Nesta altura, surgem algumas perguntas relevantes: o que garante a continuidade da nossa vida interior, e qual é a relação entre consciência e eventos psíquicos inconscientes?

Se a consciência é uma coleção de episódios separados de curta duração, o que acontece com minha interioridade e com meu próprio eu, que até parece ficar dissolvido? Obviamente não é assim. A sua continuidade é garantida pelo conjunto de processos paralelos que têm a ver com nosso sistema nervoso central e, mais em geral, com nosso corpo, e que agem em todas as circunstâncias, mesmo durante o sono. Cada vez uma fração destes processos é serializada, emergindo à consciência por alguns segundos. O episódio em questão termina, mas a continuidade dos processos nervosos paralelos garante que haja sempre um novo episódio que nos diga respeito. O que, dentre outras coisas, caracteriza univocamente tal complexo de processos paralelos é o conjunto das recordações pessoais, que pertencem a um único eu. Essa identidade é posteriormente confirmada de maneira contínua por observarmos o próprio corpo e por constatarmos que os outros nos reconhecem e nos tratam sempre da mesma R. Inter. Interdisc. INTERthesis, Florianópolis, v.6, n.1, p. 1-14, jan./jul. 2009 
maneira. Por conseguinte, a continuidade da consciência de cada indivíduo, a saber, a sua identidade, baseia-se no conjunto dos processos paralelos que dizem respeito ao seu corpo e à sua psique, caracterizados pela continuidade e pela substancial inexauribilidade típica de todo fenômeno biológico, mas só pode ser provada através da coleção dos momentâneos episódios de consciência. Sendo assim, a sensação de sermos nós mesmos poderá ser reduzida a uma continuidade? O ipse [ele mesmo] identifica-se inteiramente com o idem [o mesmo], para usarmos uma terminologia um pouco rebuscada mas eficaz? Diria que sim, e não vejo alternativas, mesmo que eu viva o ipse.

Um estado de consciência é sempre consciência de algo, ou melhor, de algo que prevê, pelo menos potencialmente, a execução de uma ação. Isso é mais que óbvio para os estados de consciência dos animais, mas talvez não seja imediatamente evidente para a nossa consciência. No entanto, pode ser que um estado de consciência não seja nada mais que uma forma particular de percepção, ou de ideação, que seja fundamentalmente untada de projeção, obviamente de projeção de uma ação, que, aliás, pode continuar sendo virtual. Por outras palavras, pode acontecer que todo episódio de consciência participe contemporaneamente da natureza da percepção e daquela da projeção, da contemplação e da motricidade, do observar e do fazer, e que seja diferente de qualquer outro evento nervoso e mental por esse seu sabor misto, devido ao fato de nele estarem misturadas, em igual medida, observação e ação. Conseqüência disso é que tal constatação aproxima muito entre si consciência e linguagem, sendo esta uma outra faculdade, agora exclusivamente humana, que une a observação e a imaginação, constitutivas do momento da recepção, com a motricidade, a qual é o pressuposto da ação programada e controlada.

É quase inevitável, portanto, que no momento em que está presente em nossa consciência, um determinado estado de coisas, externas ou internas, tenha também uma conotação afetiva, confrontando-se assim com uma realidade emotiva. Mas, o que é uma emoção? Frente a um perigo ou a uma oportunidade especialmente atraente, são liberadas em nosso corpo substâncias especiais que alteram seu estado geral de alerta e a disposição de cumprir determinadas ações. Os seres humanos percebem tal estado de coisas e muitas vezes chegam a uma apreciação consciente do fenômeno, que chamamos emoção, ou, de forma mais geral, estado emotivo. O impulso emotivo age também quando não é consciente, 
mas nesse caso não se fala de emoção. O envolvimento emotivo é muito forte, quer seja percebido como tal, quer fique no plano inconsciente e, por conseguinte, seja puramente somático. Quase toda nossa ação vem acompanhada de uma conotação emotiva mais ou menos intensa, e são as emoções que, prevalecentemente, nos levam a agir de um modo ou de outro. Uma constelação de estados emotivos que giram em torno do mesmo objeto assume em geral o nome de sentimento. Convém notar que nos organismos inferiores as emoções se originam apenas como resposta aos acontecimentos da sua vida real. Uma das prerrogativas do ser humano consiste em reagir emotivamente também frente a fatos imaginados, esperados ou simplesmente projetados na mente, em base, por exemplo, a um juízo de valor mais ou menos explícito.

Um dado estado de consciência pode estar associado a uma emoção profunda, da qual nos podemos eventualmente dar conta, ou encontrar um eco interior quase imperceptível que representa um resíduo parcialmente paralelo de associações com eventos, sensações e pensamentos que não estão presentes com clareza à memória de trabalho do momento. Essa multíplice conotação emotiva, virtualmente não eliminável, constitui a essência da nossa consciência fenomênica individual. Colocada nestes termos, nem sequer fica claro se a chamada consciência fenomênica é sob todos os sentidos uma consciência. De qualquer modo, nossa vida emotiva somática nunca nos abandona, guiando-nos silenciosamente em todo instante da nossa jornada, mas, para emergir à consciência, deve aproveitar-se dos eventos de serialização que envolvam elementos mais diretamente associados a ela. Em suma, o coração age subterraneamente com uma ação persistente e contínua. A vida mental e a consciência são, por sua vez, apenas uma coleção de episódios de duração limitada, pequenas ilhas de serialidade que afloram momentaneamente do mare magnum [grande mar] do sub-simbólico e do paralelo.

É sob essa luz que podemos considerar o conceito de inconsciente. A rigor, ele seria tudo aquilo que fica fora de um determinado episódio de consciência. É interessante perguntar a essa altura o que se deve compreender com este termo. Certamente são inconscientes todos os processos fisiológicos que acontecem em nosso corpo e que não têm nenhuma relação com nossa vida mental. Também são inconscientes os processos fisiológicos que têm uma influência apenas indireta sobre nosso sistema nervoso, como é o caso daqueles mediados por hormônios ou R. Inter. Interdisc. INTERthesis, Florianópolis, v.6, n.1, p. 1-14, jan./jul. 2009 
neuromoduladores de ação lenta. São inconscientes os neuroestados em sua grande maioria, embora muitos deles estejam sempre potencialmente prontos a emergir em um estado de consciência. Entre estes talvez seja útil distinguir os que derivam de estímulos sensoriais imediatos - que, aliás, não são numerosos daqueles que se originam da chamada à memória de trabalho de conceitos e sensações já presentes na nossa mente.

Por outro lado, é verossímil que estes últimos estejam organizados em grupos de associação ou de contigüidade, por exemplo, temporal. A vantagem imediata dessa organização é a possibilidade de revocar velozmente à memória imagens, conceitos e nomes. Mas também é concebível que o mecanismo tenha uma viscosidade própria e alguns neuroestados sejam, por assim dizer, arrastados passivamente por outros, mesmo que tudo isso não pareça ter uma utilidade imediata. Se isso for verdade, como me parece muito provável, o grupo de neuroestados, que conflui a cada dado momento em um psicoestado, arrasta consigo, mais ou menos energicamente, um certo número de outros neuroestados, que não podem alcançar aquele especial estado de consciência, mas que se encontram nas imediatas proximidades, digamos "no seu entorno". Muitos deles podem contribuir para aquela conotação cognitiva e afetiva de que falava antes e que constitui, instante por instante, o nosso mundo interior, mutante, mas contínuo. Provavelmente é sensato chamar, operativamente, de inconsciente em sentido próprio, tanto cognitivo quanto afetivo, este conjunto de neuroestados que orbitam, instante por instante, em volta dos diferentes estados de consciência. Conseqüência disso é que, se na mente de um sujeito existem grupos específicos de neuroestados que são bastante estreitamente associados a muitíssimos outros, estes terão maior probabilidade do que outros de aproximar-se da consciência, mas também de comparecer entre os neuroestados "no seu entorno". Trata-se, nesse caso, de um "pensamento dominante" e/ou de um "conjunto", operantes tanto cognitiva quanto afetivamente, e potencialmente capazes de assumir o controle de determinados aspectos da vida mental de um indivíduo. O papel de uma psicoterapia, de tipo dinâmico ou cognitivista, deveria ser então o de reorganizar, onde fosse necessário, as relações entre tais grupos de associação, e atenuar, nessa ocorrência, uma eventual e tirânica prevalência de algum deles.

Dossiê: Recebido em: 13/04/2009 Aceito em: 24/06/2009 